https://helda.helsinki.fi

\title{
The current status of hormonal therapies for heavy menstrual bleeding
}

\section{Heikinheimo, Oskari}

2017-04

Heikinheimo, O \& Fraser , I 2017 , ' The current status of hormonal therapies for heavy

menstrual bleeding ' , Best Practice \& Research: Clinical Obstetrics \& Gynaecology , vol. 40 , pp. 111-120 . https://doi.org/10.1016/j.bpobgyn.2017.01.001

http://hdl.handle.net/10138/236953

https://doi.org/10.1016/j.bpobgyn.2017.01.001

publishedVersion

Downloaded from Helda, University of Helsinki institutional repository.

This is an electronic reprint of the original article.

This reprint may differ from the original in pagination and typographic detail.

Please cite the original version. 
9

\title{
The current status of hormonal therapies for heavy menstrual bleeding
}

\author{
Oskari Heikinheimo, MD, PhD, Professor, Physician in-Chief ${ }^{a}$, , \\ Ian Fraser, MD, PhD, Conjoint Professor (Reproductive \\ Medicine) ${ }^{\mathrm{b}}$
}

\footnotetext{
a Department of Obstetrics and Gynaecology, University of Helsinki and Kätilöopisto Hospital, Helsinki University Central Hospital, P.O. Box 610, 00029-HUS, Helsinki, Finland

${ }^{\mathrm{b}}$ University of New South Wales, School of Women's and Children's Health, Royal Hospital for Women, Randwick, Sydney, NSW 2031, Australia
}

\section{Keywords:}

heavy menstrual bleeding

levonorgestrel-releasing intrauterine sys-

tem

treatment guideline

estradiol-containing oral contraceptive
Hormonal treatment of abnormal uterine bleeding (AUB), especially bleeding related to endometrial causes (AUB-E), ovulatory dysfunction (AUB-O) and coagulopathy (AUB-C), and to some extent, uterine leiomyomas and adenomyosis, has become the first-line evidence-based management strategy during recent years. Hormonal treatment of heavy menstrual bleeding (HMB) is also endorsed as the first line of treatment in several international guidelines.

In the present article, we review the efficacy of the commonly used and widely available hormonal treatments of AUB-O, AUB-E and AUB-C. The therapies include combined hormonal contraceptives, progestin-only preparations, and intrauterine release of levonorgestrel through the levonorgestrel-releasing intrauterine system. In addition, we make practical recommendations for patient management.

We also review some of the current guidelines and their recommendations concerning the treatment of HMB. Finally, the effects of hormonal treatment on the overall management of AUB and its effects on the health care system and specialist training are discussed.

() 2017 Published by Elsevier Ltd.

\footnotetext{
* Corresponding author. Kätilöopisto Hospital, Helsinki University Hospital, P.O. Box 610, 00029-HUS, Helsinki, Finland. Tel.: +358 405871070.

E-mail address: oskari.heikinheimo@helsinki.fi (O. Heikinheimo).
} 


\section{Treatment of heavy menstrual bleeding}

\section{Combined hormonal contraceptives}

\section{Ethinylestradiol-containing preparations}

The use of combined oral contraceptives (COCs) reduces uterine bleeding in healthy women by approximately 40\% during 6 months of use [1]. The endometrial mechanism(s) of action of COCs in reducing menstrual flow involve the downregulation of endometrial estrogen receptors resulting in atrophic glandular endometrium because of prolonged progestin exposure of the endometrium [2].

The therapeutic use of ethinylestradiol-containing COCs in the treatment of heavy menstrual bleeding (HMB) has been compared to that of the levonorgestrel (LNG)-releasing intrauterine system (LNG-IUS) in recent studies from Canada [3] and Egypt [4]. In the Egyptian study, use of a COC containing $30 \mu \mathrm{g}$ of EE and $150 \mu \mathrm{g}$ of LNG resulted in a decrease of $35 \%$ in the measured blood loss during 1 year of follow-up assessed by the alkaline hematin method [4]. The Canadian study, using a COC containing $20 \mu \mathrm{g}$ of EE and $1 \mathrm{mg}$ of northisterone acetate, reported a 68\% decrease in menstrual blood loss during 1 year of use [3].

In addition, treatment of HMB using a vaginal ring (Nuva Ring ${ }^{\circledR}, \mathrm{MSD} / \mathrm{Merck}$ ) releasing $15 \mu \mathrm{g}$ of EE and $120 \mu \mathrm{g}$ of etonogestrel $v s$. long-cycle northisterone acetate (5 mg t.i.d. on cycle days 5-26) was assessed in an Egyptian study [5]. Both treatments were equally effective in reducing the menstrual blood loss during the 3-month study with 69\% vs. 70\% decline in PBAC score, respectively. However, use of the vaginal ring was significantly better tolerated and had a high (77\%) continuation rate [5].

\section{Estradiol-containing preparations}

Novel combined contraceptive preparations containing estradiol instead of ethinylestradiol are also efficacious in treating HMB. Withdrawal bleeding was absent in approximately $20 \%$ of the women with the use of estradiol valerate- and dienogest-containing COC [6] and in up to $30 \%$ of the women with the use of $17 \beta$-estradiol- and nomegestrole acetate-containing COC [7].

In a large placebo-controlled multicentre trial performed in women suffering from documented $\mathrm{HMB}$, estradiol valerate- and dienogest-containing COC reduced menstrual bleeding by approximately $60 \%$ in 6 months of use [8]. Treatment of HMB is also an approved indication for the commercially available preparation containing estradiol and dienogest. However, COCs containing estradiol vs. ethinylestradiol or the possible role of the progestin component of COCs have not been tested in randomized trials.

A commonly used but little-researched strategy is the long-cycle use of combined hormonal contraceptives (CHCs) [9]. Although reduction of menstrual bleeding is often cited a clinical advantage, no randomized trials have assessed the efficacy of long-cycle CHCs in the treatment of HMB.

Table 1 summarizes the overall reduction in menstrual flow with the use of different hormonal preparations in women with HMB. The reduction in HMB and the length of the various studies according to the type of hormonal treatment are highlighted in Figure 1.

\section{Progestins}

Cyclic luteal-phase administration of progestin remained a widely used but little-researched treatment strategy for HMB for several decades. However, scientific studies comparing luteal (i.e., 10-14 days/mo) with NSAIDs, tranexamic acid, or LNG-IUS have revealed that luteal-phase progestin has minimal or no effect on the bleeding and is no longer considered a valid treatment option for HMB [10].

Extended (i.e., cycle days 5-26) use of progestin with $5 \mathrm{mg}$ of NETA three times a day (t.i.d.) was compared to the intrauterine release of LNG by LNG-IUS in a study by Irvine et al. [11]. Three months of extended use of NETA reduced the measured blood loss by $87 \%$ among women with documented HMB. However, satisfaction with the extended NETA treatment was poor, and only few women (i.e., $22 \%$ ) chose to continue the treatment. Similarly, comparison of EE- and etonogestrel-releasing vaginal ring and extended use of NETA in HMB treatment revealed significantly lower acceptance and continuation rate of the NETA [5]. Thus, extended use of progestin provides an effective but poorly tolerated systemic therapy for HMB. 
Table 1

Efficacy of the various hormonal therapies in reducing measured menstrual blood loss (by alkaline hematin method) in women with documented HMB.

\begin{tabular}{|c|c|c|c|c|}
\hline & $\begin{array}{l}\text { Reduction in } \\
\text { menstrual } \\
\text { blood loss }\end{array}$ & $\begin{array}{l}\text { Duration of } \\
\text { treatment }\end{array}$ & Comparator & Reference \\
\hline \multicolumn{5}{|l|}{ Combined hormonal preparations } \\
\hline Ethinylestradiol-containing COC & $35 \%$ & $12 \mathrm{mo}$ & Before and after & Shabaan et al., 2011 [4] \\
\hline $\begin{array}{l}\text { Estradiol valerate- and dienogest- } \\
\text { containing COC }\end{array}$ & $60 \%$ & $7 \mathrm{mo}$ & Before and after & Fraser et al., 2012 [8] \\
\hline \multicolumn{5}{|l|}{ Progestin-only preparations } \\
\hline Luteal-phase progestin & $\begin{array}{l}\text { Inferior to } \\
\text { active } \\
\text { comparators } \\
22 \%\end{array}$ & $6 \mathrm{mo}$ & $\begin{array}{l}\text { Tranexamic acid, } \\
\text { danazol } \\
\text { Before and after }\end{array}$ & $\begin{array}{l}\text { Lethaby, } 2008 \text { [10] } \\
\text { Kaunitz et al., } 2010 \text { [24] }\end{array}$ \\
\hline $\begin{array}{l}\text { Extended cycle progestin (i.e., NETA } \\
5 \mathrm{mg} \text { t.i.d. on cycle days } 5-26 \text { ) }\end{array}$ & $87 \%$ & $3 \mathrm{mo}$ & Before and after & Irvine et al., 1998 [11] \\
\hline LNG-IUS & $86 \%-97 \%$ & $6-12 \mathrm{mo}$ & Before and after & $\begin{array}{l}\text { Andersson and Rybo, } 1990 \text { [14] } \\
\text { Milsom et al., 1991 [15] } \\
\text { Reid \& Virtanen-Kari 2005 [35] } \\
\text { Shabaan et al., } 2011 \text { [4] } \\
\text { Kaunitz et al., } 2010 \text { [24] }\end{array}$ \\
\hline
\end{tabular}

Intrauterine release of progestin

Studies on the intrauterine release of LNG for contraception through intrauterine device began in the 1970s [12]. When testing the first experimental LNG-IUS, it soon became evident that uterine bleeding is strongly reduced with LNG-IUS use [13]. The therapeutic potential of the LNG-IUS was rapidly tested in women suffering from HMB by Andersson and Rybo [14] and Milsom et al. [15]. A mean reduction of $82 \%$ in uterine bleeding was observed during the first 3 months of LNG-IUS use. Thus a suggestion that the LNG-IUS can be an important alternative to oral medication and hysterectomy in the treatment of HMB was made in the early 1990s.

\section{The LNG-IUS in the treatment of heavy menstrual bleeding}

\section{Mechanism of action}

The mechanism(s) by which intrauterine release of LNG reduces uterine bleeding have been studied intensively since the 1970s. In the first histological studies, a strong suppression of the endometrial epithelium and glands was seen with LNG-IUS use. However, the stroma was marked by intense decidual reaction, which is typical of early pregnancy [16]. In addition, the LNG-exposed endometrial stroma expressed similar markers of decidualization as that of first trimester of pregnancy [17].

The mediators of sex steroid action, namely steroid receptors and steroid-metabolizing enzymes, in endometrium are altered with LNG-IUS use. There is a marked downregulation of both epithelial and stromal expression of estrogen and progesterone receptors [18]. An increased expression of endometrial $17 \beta$-hydroxysteroid dehydrogenase type 2 , which is responsible for converting estradiol into estrone, has been described [19]. These alterations possibly reduce the proliferative effects of estradiol on endometrium and explain in part the endometrial suppression and reduced bleeding with LNG-IUS use.

In addition, stromal expression of insulin-like growth factor-binding protein-1 is upregulated with LNG-IUS use. This may result into the sequesteration of endometrial insulin-like growth factor-1 (IGF1 ), thereby reducing the proliferative effects of IGF-1. This may be one of the mechanisms resulting in the suppression of endometrial epithelium with LNG-IUS use [20].

The LNG-IUS also has an effect on the endometrial levels of various hemostatic factors. Specifically, endometrial content of u-PAR and PAI- 1 and 2 was significantly increased after 1 month of LNG-IUS use [21]. However, the effects of LNG-IUS on angiogenic growth factor(s) are less clear. Both an increase and 
decrease in the endometrial content/expression of vascular endothelial growth factor has been described with LNG-IUS use [22,23].

LNG-IUS in comparison to medical treatments in the treatment of HMB

A landmark paper by Kaunitz et al. [24] compared the use of LNG-IUS and cyclic oral progestin (10 mg MPA/day on cycle days 16-25) among women with documented HMB. Treatment with LNG-IUS resulted in a mean reduction of $71 \%$ of measured monthly blood loss in comparison to $22 \%$ among women randomized for cyclic MPA; the treatment outcome was judged successful in $85 \%$ of the women randomized to LNG-IUS and in $22 \%$ of the women randomized to cyclic progestin.

Gupta et al. [25] compared LNG-IUS with conventional medical therapies (tranexamic acid, mefenamic acid, and combined preparations of estrogen and progestin or progestin-only) in the

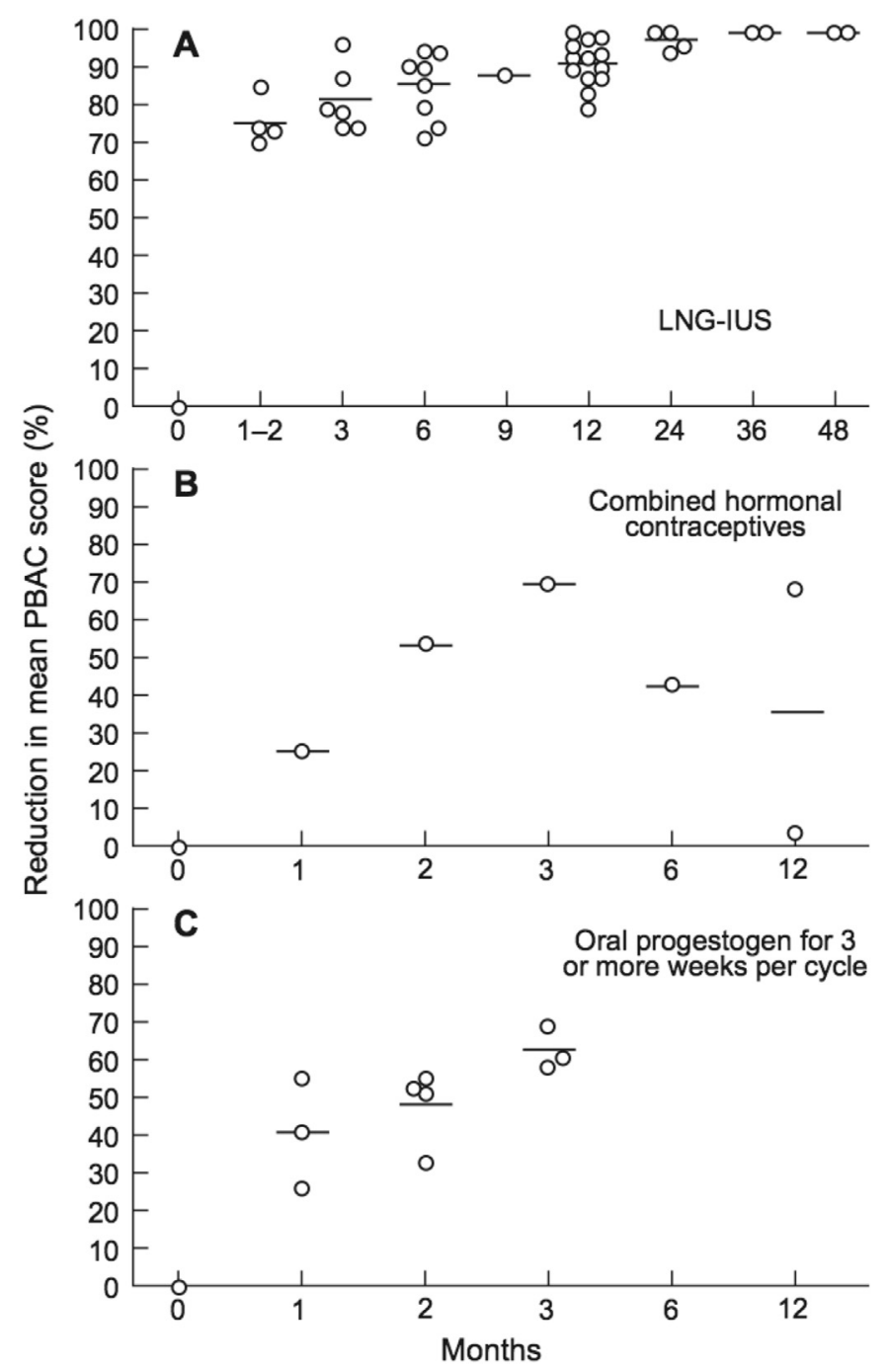

Fig. 1. Mean reductions in menstrual bleeding (measured by pictorial Blood loss Assessment Chart score) according to the duration of treatment in women suffering from AUB-E and being treated with a. LNG-IUS b. CHCs c. Oral progestins $\geq 21$ days/cycle Please note the different time scales in the three panels. Modified with permission from Bitzer et al. [31]. 
treatment of HMB in a randomized study performed in a primary care center [25]. In this pragmatic study, eligible women were randomized for receiving LNG-IUS and conventional medical therapy to be decided by the treating physician. The primary outcome measure-patient-reported Menorrhagia Multi-attribute Scale-increased in both groups. However, the increase was significantly greater in the LNG-IUS group. In addition, the quality of life indices and continuation of method use at 2 years (64\% vs. $38 \%$, respectively) were significantly higher in the LNG-IUS group than in the usual-care group.

LNG-IUS in comparison to surgical treatments in the treatment of HMB

\section{Endometrial ablation}

Kaunitz et al. [26] compared LNG-IUS with endometrial ablation therapy in the treatment of HMB in a meta-analysis of six randomized trials. The reduction in menstrual bleeding was similar following the two treatment strategies up to 2 years of follow-up. Similarly, improvement in the quality of life did not differ between the treatment groups. Both treatment strategies were not associated with major complications.

\section{Hysterectomy}

Although the idea of using LNG-IUS instead of hysterectomy in the treatment of HMB was introduced in 1990 [14], the first prospective study concerning the use of LNG-IUS instead of hysterectomy was published in 1998 [27]. In the study by Lähteenmäki et al. [27], altogether 56 women scheduled for hysterectomy for the treatment of excessive uterine bleeding were randomized to continue their current treatment (i.e., surgery) or the insertion of LNG-IUS. The primary outcome measure was the rate of hysterectomies cancelled by 6 months. Of the women randomized to the LNG-IUS, $64 \%$ cancelled the operation compared to only $14 \%$ in the control group $(\mathrm{p}<0.001)$. Thus, the authors concluded that LNG-IUS is a good alternative to hysterectomy in the treatment of menorrhagia and should be considered before invasive treatment [27].

A randomized Finnish multicentre study compared the efficacy and long-term outcomes of LNGIUS and hysterectomy among women referred to hospital for hysterectomy because of HMB [28]. Altogether 236 women consented for the study and were randomized to receive treatment for HMB with LNG-IUS or hysterectomy. At 1 year of follow-up, $20 \%$ and $91 \%$ of the women randomized to LNGIUS and hysterectomy, respectively, had undergone hysterectomy. At 5 years, the corresponding figures were $42 \%$ and $93 \%$ [29]. The various outcomes of health-related quality of life (HRQL) were similar between the two groups. Nevertheless, the overall health-related costs were significantly lower among women randomized to the LNG-IUS (mean 2817 vs. 4660 USD). Thus, the authors concluded that by providing improvement in HRQL at relatively low cost, the LNG-IUS may offer wider availability of choices for the patient and may decrease costs due to interventions involving surgery [29].

A recently updated Cochrane review assessed altogether 15 parallel-group research studies comparing medical therapy (oral medications or the LNG-IUS)and surgical treatment (endometrial resection or hysterectomy) for HMB [30]. There were altogether 11 studies that evaluated the LNG-IUS. The review concluded that following surgical treatment, there was more objective control of bleeding at 1 year. However, the quality of life at 5 or 10 years did not differ between women assigned to the LNG-IUS and surgical treatments. Concerning adverse events of complications, surgical treatment was associated with an increased risk of surgical complications (such as organ perforation), whereas the use of LNG-IUS had a risk of insufficient therapeutic effect (i.e., on-going bleeding) or associated subjective hormonal side effects. The Cochrane review concluded that although surgery provides an effective long-term therapeutic effect, the LNG-IUS provides a better alternative to surgery for most women suffering from HMB.

A recent comprehensive review on the medical management of HMB by Bitzer et al. [31] proposed a treatment algorithm for women suffering from abnormal uterine bleeding (AUB) because of endometrial causes (AUB-E) or coagulopathies (AUB-C). The algorithm (Fig. 2) takes into account women's different wishes (such as wish for pregnancy) and preferences (such as acceptance of intrauterine treatment). 


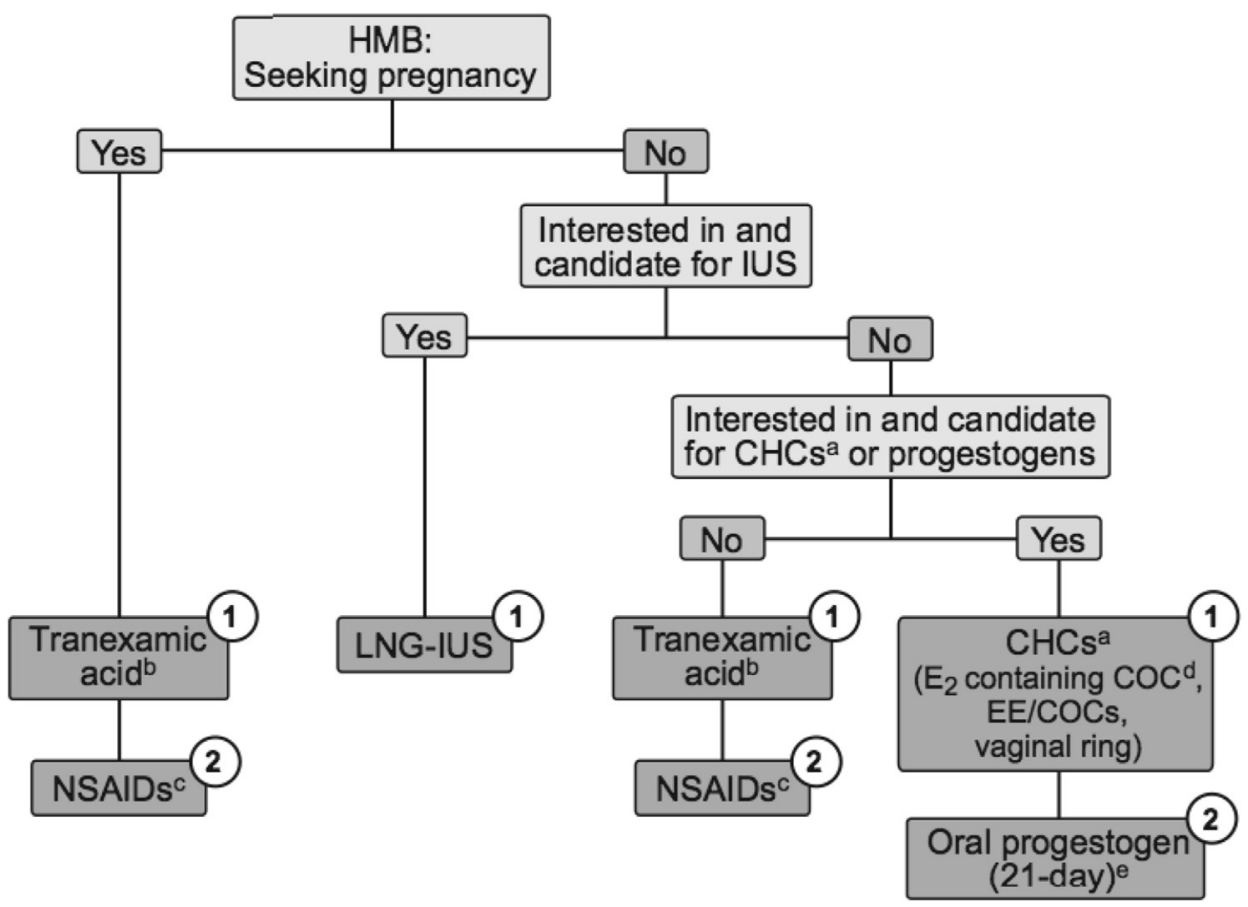

Fig. 2. Algorithm on the medical treatment of AUB-E or AUB-C in various clinical circumstances. The most effective treatment in terms of reduction of HMB is indicated by the number 1 and the second-most effective by the number 2. (a) please note the possible contraindications to CHCs; (b) and (c) nonhormonal options, do not act as contraceptives; (c) may be the first choice in cases of associated dysmenorrhea; (d) treatment of HMB is an official indication for the preparation containing estradiol valerate and dienogest; and (e) may not function as a contraceptive. Modified with permission from Bitzer et al. [31].

\section{International guidelines on the treatment of HMB}

There are several international guidelines on the treatment of AUB/HMB (Table 2). In addition, several Cochrane reviews have assessed the efficacy of hormonal treatment in the treatment of AUB

Table 2

National guidelines on the treatment of AUB/HMB. Summary of the recommendations concerning in hormonal treatment. All guidelines included promote the use of medical therapy as the first-line treatment strategy.

\begin{tabular}{|c|c|c|c|c|c|}
\hline & Canada & Finland & France & UK/NICE & USA/ACOG** \\
\hline $\begin{array}{l}\text { Type of AUB } \\
\text { covered }\end{array}$ & AUB & HMB & HMB & HMB & AUB-O \\
\hline \multicolumn{6}{|c|}{ Order of efficacy (if recommended) } \\
\hline $\mathrm{COC}$ & 'reduce effectively' & 'recommended' & 3. & 2. & 2. \\
\hline $\begin{array}{l}\text { Luteal-phase } \\
\text { progestin }\end{array}$ & 'not effective' & 'not effective' & NA & 'not to be used' & 3. \\
\hline $\begin{array}{l}\text { Extended-cycle } \\
\text { progestin }\end{array}$ & 'reduce effectively' & 'recommended' & 4. & 3. & \\
\hline DMPA & 'reduce effectively' & 'not recommended' & NA & 3. & \\
\hline LNG-IUS & 'reduce effectively' & 'recommended'* & 1. & 1. & 1. \\
\hline $\begin{array}{l}\text { Tranexamic } \\
\text { acid }\end{array}$ & 'can be used' & 'recommended' & 2. & 2. & 2. \\
\hline NSAID & 'can be used' & 'recommended' & 5. & 2. & 3. \\
\hline Reference & $\begin{array}{l}\text { Singh et al., } 2013 \\
\text { [36] }\end{array}$ & $\begin{array}{l}\text { www.kaypahoito.fi } \\
\text { [37] }\end{array}$ & $\begin{array}{l}\text { Marret et al., } 2010 \\
\text { [38] }\end{array}$ & $\begin{array}{l}\text { www.nice.org.uk } \\
\text { [39] }\end{array}$ & $\begin{array}{l}\text { ACOG Practice bulletin, } \\
2013[40]\end{array}$ \\
\hline
\end{tabular}

* LNG-IUS should be tried before the surgical treatment of HMB is undertaken.

** The American College of Obstetricians and Gynecologists. 


\section{Annual number of hysterectomy and LNG-IUS (i.e. Mirena ${ }^{\circledR}$ ) units sold in Finland 1997-2012}

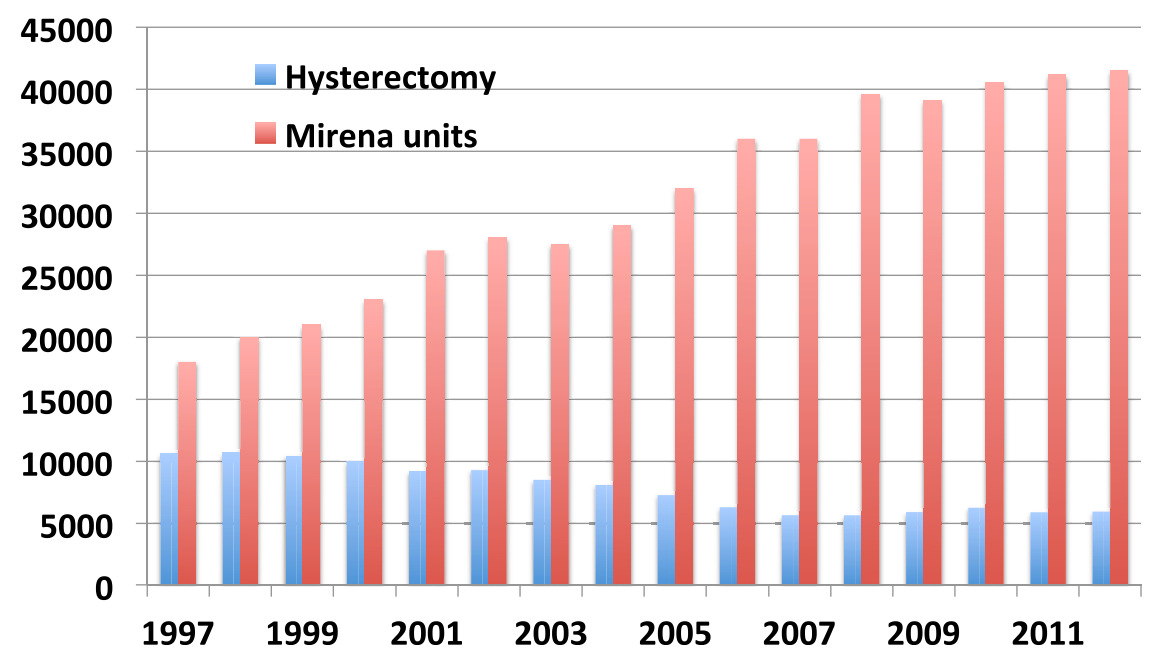

Fig. 3. Annual number of hysterectomies and the number of Mirena ${ }^{\circledR}$-units (Bayer AG, Turku, Finland) sold in Finland in $1997-2012$.

\section{Publication of the key documents on medical treatment of $\mathrm{HMB}$ and the annual number of hysterectomies in Finland 1997-2012}

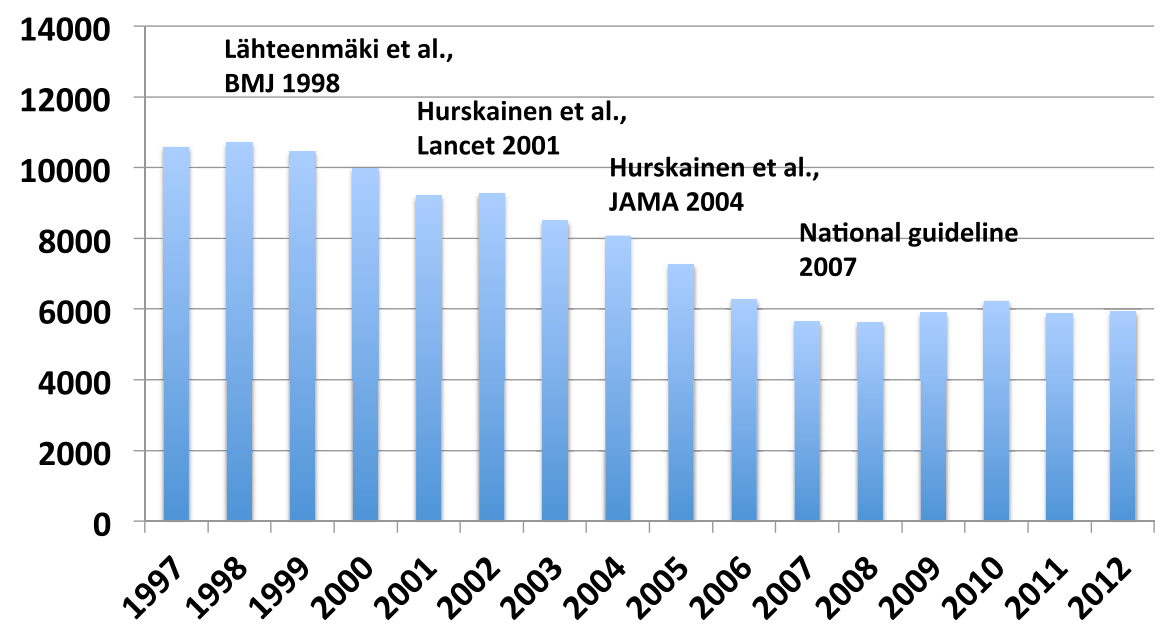

Fig. 4. Publication of the key articles on the use of LNG-IUS in the treatment of HMB and the national guideline on the treatment of HBM vs. the annual number of hysterectomies in Finland in 1997-2012. 
[32]. Of the guidelines ranking the hormonal treatments of HMB according to their efficacy, all rank LNG-IUS as the most effective hormonal treatment for HMB (Fig. 3).

\section{The effect of systematic research and treatment guidelines on clinical practice}

Research studies assessing the efficacy of hormonal treatment of AUB often recruit patients according to the etiology of the bleeding disturbance. However, in daily clinical practice, this is often difficult and treatments are sought according to suspected or most likely etiology.

Since the introduction of medical treatment of HMB and treatment guidelines, several countries have witnessed a marked decline in the rate of hysterectomy. For example, in Australia and Italy, the rate of hysterectomy has decreased by approximately $40 \%$ in the recent decades [33,34].

Figure 4 highlights the annual number of hysterectomies performed for benign diseases in Finland. In addition, publications of major Finnish research studies comparing the treatment of AUB by LNG-IUS with hysterectomy and publication of the national guideline on the evaluation and treatment of MHD are shown in Figure 4. Similarly, the rate of annual number of hysterectomies has declined approximately $40 \%$, from 10,000 annual hysterectomies in the late 1990 s to approximately 6000 during the 2010s.

Thus, medical treatment of HMB and its active promotion have significantly reduced the need of surgical treatment of AUB. These changes are likely to continue with the availability of novel medications to control uterine diseases and bleeding symptoms. These changes are also increasingly reflected in the curriculum of specialist training programs in obstetrics and gynecology.

\section{Conflict of interest statement}

$\mathrm{OH}$ has occasionally served on advisory boards or as invited speaker in educational events organized by Bayer Healthcare, MSD/Merck, Actavis, Exelgyn, Gedeon Richter, and Sandoz.

ISF has served on advisory boards, has given lectures, and received expenses and honoraria from Bayer Healthcare, MSD/Merck, Daiichi Sankyo, Vifor Pharma, and Teva Pharmaceuticals.

\section{Practice points}

- LNG-IUS is the most effective and long-lasting option for the hormonal treatment of HMB.

- $\mathrm{CHCs}$, especially those containing estradiol valerate, are also effective in reducing menstrual bleeding by approximately $60 \%$.

- Promotion of hormonal treatment and publication of national and international guidelines on the treatment of HMB have reduced the need for hysterectomy in several countries.

\section{Research agenda}

- Novel hormonal mediations such as selective progesterone receptor modulators in HMB

- The impact of conservative treatment of AUB and its active promotion on the need for specialist training and training curricula.

\section{Summary}

Hormonal therapy by CHCs, long-cycle progestins, or intrauterine release of LNG through LNG-IUS has become the first-line treatment for HMB. Several research studies have shown that the LNG-IUS provides the most efficacious and long-lasting option for the hormonal treatment of HMB. The menstrual blood flow is reduced by approximately 95\% during the first year of use among women suffering 
from HMB. Moreover, the LNG-IUS provides an effective therapy for at least up to 5 years. CHCs, especially those containing estradiol valerate, are also efficacious and reduce the volume of menstrual flow in women with documented HMB by approximately $60 \%$.

Medical treatment of HMB has been endorsed as the first line of treatment for HMB by several national and international practice guidelines on HMB during the last decade. Treatment by LNG-IUS has been ranked as the most effective by all guidelines recommending therapies according to their efficacy. Such endorsements are rapidly altering the treatment strategies of HMB, resulting in reduced need of surgical treatments including hysterectomy. Decreasing need of surgical treatment is currently also affecting the requirements and curriculum of specialist trainings in obstetrics and gynecology and the structure of health care systems.

\section{References}

[1] Larsson G, Milsom I, Lindstedt G, et al. The influence of a low-dose combined oral contraceptive on menstrual blood loss and iron status. Contraception 1992;46(4):327-34.

[2] Dinh A, Sriprasert I, Williams AR, et al. A review of the endometrial histologic effects of progestins and progesterone receptor modulators in reproductive age women. Contraception 2015;91(5):360-7.

[3] Endrikat J, Shapiro H, Lukkari-Lax E, et al. A Canadian, multicentre study comparing the efficacy of a levonorgestrelreleasing intrauterine system to an oral contraceptive in women with idiopathic menorrhagia. J Obstet Gynaecol Can 2009;31(4):340-7.

[4] Shaaban MM, Zakherah MS, El-Nashar SA, et al. Levonorgestrel-releasing intrauterine system compared to low dose combined oral contraceptive pills for idiopathic menorrhagia: a randomized clinical trial. Contraception 2011;83(1): 48-54.

[5] Abu Hashim H, Alsherbini W, Bazeed M. Contraceptive vaginal ring treatment of heavy menstrual bleeding: a randomized controlled trial with norethisterone. Contraception 2012;85(3):246-52.

[6] Ahrendt HJ, Makalová D, Parke S, et al. Bleeding pattern and cycle control with an estradiol-based oral contraceptive: a seven-cycle, randomized comparative trial of estradiol valerate/dienogest and ethinyl estradiol/levonorgestrel. Contraception 2009;80(5):436-44.

*[7] Westhoff C, Kaunitz AM, Korver T, et al. Efficacy, safety, and tolerability of a monophasic oral contraceptive containing nomegestrol acetate and 17ß-estradiol: a randomized controlled trial. Obstet Gynecol 2012;119(5):989-99.

*[8] Fraser IS, Jensen J, Schaefers M, et al. Normalization of blood loss in women with heavy menstrual bleeding treated with an oral contraceptive containing estradiol valerate/dienogest. Contraception 2012;86(2):96-101.

[9] Gerschultz KL, Sucato GS, Hennon TR, et al. Extended cycling of combined hormonal contraceptives in adolescents: physician views and prescribing practices. J Adolesc Health 2007;40(2):151-7.

[10] Lethaby A, Irvine GA, Cameron IT. Cyclical progestogens for heavy menstrual bleeding. Cochrane Database Syst Rev 2008; (1), CD001016. http://dx.doi.org/10.1002/14651858.CD001016.pub2.

[11] Irvine GA, Campbell-Brown MB, Lumsden MA, et al. Randomised comparative trial of the levonorgestrel intrauterine system and norethisterone for treatment of idiopathic menorrhagia. Br J Obstet Gynaecol 1998;105(6):592-8.

[12] Nilsson CG, Johansson ED, Luukkainen T. A D-norgestrel-releasing IUD. Contraception 1976;13(4):503-14.

[13] Nilsson CG. Comparative quantitation of menstrual blood loss with a d-norgestrel-releasing iud and a Nova-T-copper device. Contraception 1977; 15(4):379-87.

[14] Andersson JK, Rybo G. Levonorgestrel-releasing intrauterine device in the treatment of menorrhagia. Br J Obstet Gynaecol 1990;97(8):690-4.

*[15] Milsom I, Andersson K, Andersch B, et al. A comparison of flurbiprofen, tranexamic acid, and a levonorgestrel-releasing intrauterine contraceptive device in the treatment of idiopathic menorrhagia. Am J Obstet Gynecol 1991;164(3): 879-83.

[16] Silverberg SG, Haukkamaa M, Arko H, et al. Endometrial morphology during long-term use of levonorgestrel-releasing intrauterine devices. Int J Gynecol Pathol 1986;5(3):235-41.

[17] Critchley HO, Wang H, Jones RL, et al. Morphological and functional features of endometrial decidualization following long-term intrauterine levonorgestrel delivery. Hum Reprod 1998;13(5):1218-24.

[18] Engemise SL, Willets JM, Taylor AH, et al. Changes in glandular and stromal estrogen and progesterone receptor isoform expression in eutopic and ectopic endometrium following treatment with the levonorgestrel-releasing intrauterine system. Eur J Obstet Gynecol Reprod Biol 2011;157(1):101-6.

[19] Burton KA, Henderson TA, Hillier SG, et al. Local levonorgestrel regulation of androgen receptor and 17beta-hydroxysteroid dehydrogenase type 2 expression in human endometrium. Hum Reprod 2003;18(12):2610-7.

[20] Pekonen F, Nyman T, Lähteenmäki P, et al. Intrauterine progestin induces continuous insulin-like growth factor-binding protein-1 production in the human endometrium. J Clin Endocrinol Metab 1992;75(2):660-4.

[21] Koh SC, Singh K. The effect of levonorgestrel-releasing intrauterine system use on menstrual blood loss and the hemostatic, fibrinolytic/inhibitor systems in women with menorrhagia. J Thromb Haemost 2007;5(1):133-8.

[22] Roopa BA, Loganath A, Singh K. The effect of a levonorgestrel-releasing intrauterine system on angiogenic growth factors in the endometrium. Hum Reprod 2003;18(9):1809-19.

[23] Laoag-Fernandez JB, Maruo T, Pakarinen P, et al. Effects of levonorgestrel-releasing intra-uterine system on the expression of vascular endothelial growth factor and adrenomedullin in the endometrium in adenomyosis. Hum Reprod 2003;18(4): 694-9.

*[24] Kaunitz AM, Bissonnette F, Monteiro I, et al. Levonorgestrel-releasing intrauterine system or medroxyprogesterone for heavy menstrual bleeding: a randomized controlled trial. Obstet Gynecol 2010;116(3):625-32. 
*[25] Gupta J, Kai J, Middleton L, et al., ECLIPSE Trial Collaborative Group. Levonorgestrel intrauterine system versus medical therapy for menorrhagia. N Engl J Med 2013;368(2):128-37.

*[26] Kaunitz AM, Meredith S, Inki P, et al. Levonorgestrel-releasing intrauterine system and endometrial ablation in heavy menstrual bleeding: a systematic review and meta-analysis. Obstet Gynecol 2009;113(5):1104-16.

[27] Lähteenmäki P, Haukkamaa M, Puolakka J, et al. Open randomised study of use of levonorgestrel releasing intrauterine system as alternative to hysterectomy. BMJ 1998;316(7138):1122-6.

*[28] Hurskainen R, Teperi J, Rissanen P, et al. Quality of life and cost-effectiveness of levonorgestrel-releasing intrauterine system versus hysterectomy for treatment of menorrhagia: a randomised trial. Lancet 2001;357(9252):273-7.

*[29] Hurskainen R, Teperi J, Rissanen P, et al. Clinical outcomes and costs with the levonorgestrel-releasing intrauterine system or hysterectomy for treatment of menorrhagia: randomized trial 5-year follow-up. JAMA 2004;291(12):1456-63.

[30] Marjoribanks J, Lethaby A, Farquhar C. Surgery versus medical therapy for heavy menstrual bleeding. Cochrane Database Syst Rev 2016 Jan 29;(1), CD003855. http://dx.doi.org/10.1002/14651858.CD003855.pub3.

*[31] Bitzer J, Heikinheimo O, Nelson A, et al. Medical management of heavy menstrual bleeding: a comprehensive review of the literature. Obstetrical Gynecol Surv 2015;70(2):115-30.

[32] Lethaby A, Hussain M, Rishworth JR, et al. Progesterone or progestogen-releasing intrauterine systems for heavy menstrual bleeding. Cochrane Database Syst Rev 2015;(4), CD002126. http://dx.doi.org/10.1002/14651858.CD002126.pub3.

[33] Parazzini F, Ricci E, Bulfoni G, et al. Hysterectomy rates for benign conditions are declining in Lombardy, Italy: 1996 -2010. Eur J Obstet Gynecol Reprod Biol 2014;178:107-13.

[34] Yusuf F, Leeder S, Wilson A. Recent estimates of the incidence of hysterectomy in New South Wales and trends over the past 30 years. Aust N Z J Obstet Gynaecol 2016;56(4):420-5.

[35] Reid PC, Virtanen-Kari S. Randomised comparative trial of the levonorgestrel intrauterine system and mefenamic acid for the treatment of idiopathic menorrhagia: a multiple analysis using total menstrual fluid loss, menstrual blood loss and pictorial blood loss assessment charts. BJOG 2005;112(8):1121-5.

[36] Singh S, Best C, Dunn S, et al. Society of Obstetricians and Gynaecologists of Canada. Abnormal uterine bleeding in premenopausal women. J Obstet Gynaecol Can 2013;35:473-9.

[37] www.kaypahoito.fi/web/kh/suositukset/suositus?id=hoi50033. [Date last assessed 19 August 2016].

[38] Marret H, Fauconnier A, Chabbert-Buffet N, et al. Clinical practice guidelines on menorrhagia: management of abnormal uterine bleeding before menopause. Eur J Obstet Gynecol Reprod Biol 2010;152(2):133-7.

*[39] www.nice.org.uk/guidance/cg44/chapter/1-Guidance\#choice. [Date last assessed 19 August 2016].

[40] American College of Obstetricians and Gynecologists. Management of abnormal uterine bleeding associated with ovulatory dysfunction -practice bulletin. Obstetrics Gynecol 2013;122(1):176-85. 